Original Article

\title{
ONE-YEAR CARDIOVASCULAR OUTCOME IN PATIENTS ON CLOPIDOGREL ANTI-PLATELET THERAPY AFTER ACUTE MYOCARDIAL INFARCTION
}

\author{
Dragana Stokanovic ${ }^{1}$, Valentina N. Nikolic ${ }^{1}$, Jelena Lilic ${ }^{2}$, Svetlana R. Apostolovic ${ }^{3,4}$, Milan Pavlovic ${ }^{3,4}$, \\ Vladimir S. Zivkovic ${ }^{5}$, Dusan Milenkovic ${ }^{6}$, Dane Krtinic ${ }^{1,7}$, Gorana Nedin-Rankovic ${ }^{1}$, Tatjana Jevtovic-Stoimenov ${ }^{8}$ \\ ${ }^{I}$ Department of Pharmacology and Toxicology, University of Niš, Faculty of Medicine, Nis, Serbia \\ ${ }^{2}$ University of Niš, Faculty of Medicine, Niš,, Serbia \\ ${ }^{3}$ Department of Cardiology, University of Niš, Faculty of Medicine, Nis, Serbia \\ ${ }^{4}$ Clinic for Cardiovascular Diseases, Clinical Center Niš, Niš, Serbia \\ ${ }^{5}$ Department of Anatomy, University of Niš, Faculty of Medicine, Nǐ̌s, Serbia \\ ${ }^{6}$ Department of Emergency Medical Care Nǐ̌s, Niš, Serbia \\ ${ }^{7}$ Clinic for Oncology, Clinical Center Niš, Niš, Serbia \\ ${ }^{8}$ Department of Biochemistry, University of Niš, Faculty of Medicine, Niš, Serbia
}

\begin{abstract}
The aim of this study was to determine the risk factors in patients on clopidogrel anti-platelet therapy after acute myocardial infarction, for cardiovascular mortality, re-hospitalization and admission to emergency care unit. We followed 175 patients on dual antiplatelet therapy, with clopidogrel and acetylsalicylic acid, for 1 year after acute myocardial infarction, both STEMI and NSTEMI. Beside demographic and clinical characteristics, genetic ABCBI, CYP2C19 and CYP2C9 profile was analyzed using Cox-regression analysis. End-points used were: mortality, rehospitalization and emergency care visits, all related to cardiovascular system. During the accrual and follow-up period, 8 patients (4.6\%) died, mostly as a direct consequence of an acute myocardial infarction. Re-hospitalization was needed in 27 patients $(15.4 \%)$, in nine patients (33.3\%) with the diagnosis of re-infarction. Thirty-two patients (18.3\%) were admitted to emergency care unit due to cardiovascular causes, up to 15 times during the follow-up. NSTEMI was an independent predictor of all three events registered (mortality OR=7.4, $p<0.05$; re-hospitalization OR=2.8, $p<0.05$ ); emergency care visit $O R=2.4, p<0.05$ ). Other significant predictors were related to kidney function (urea and creatinine level, creatinine clearance), co-morbidities such as arterial hypertension and decreased left ventricular ejection fraction, as well as clopidogrel dosing regimen. As a conclusion, it may be suggested that one of the most significant predictors of cardiovascular events (mortality, re-hospitalization and emergency care visits) is NSTEMI. Besides, clopidogrel administration according to up-to-date guidelines, with high loading doses and initial doubled maintenance doses, improves 1-year prognosis in patients with AMI.
\end{abstract}

Key words: clopidogrel, acute myocardial infarction, cardiovascular outcome.

\section{Introduction}

Despite improvements in pharmacotherapy and management of patients with acute myocardial infarction, the mortality rate and the incidence of cardiovascular outcomes remain high. In Serbia, mortality is over $10 \%$, partially due to low rate of primary PCI $(22 \%)$, the most beneficial management option in these patients [1]. The rate of various cardiovascular events is the highest in the first month after the acute event, but remains significant even a year after [2]. Cardiovascular diseases are

Correspondence to: Dane Krtinic, M.D.

Department of Pharmacology and Toxicology, Faculty of Medicine

81 Dr. Zoran Đinđić Blvd, 18000 Niš, Serbia

Tel: +38163257134

E-mail: dane.krtinic@medfak.ni.ac.rs

Received August 27 ${ }^{\text {th }}, 2017$, accepted for publication September $15^{\text {th }}, 2017$ the most common cause of death in Serbia (53.3\%), out of which $18.5 \%$ account for ischemic heart disease. More than a half of this mortality $(54.0 \%)$ is caused my ACS. The highest number of newly diagnosed AMI is among patients older than $75(34.1 \%)$, in both genders. Male and female gender ratio is $1: 1.6$. The overall incidence rate is 232.2 (or 107.7 when standardized to the world population). The Nis region is characterized with very low standardized incidence rate (below 105.0), but with moderate mortality rate (31.3), the same as the country's average [1]. The majority of the patients with AMI are treated according to the evidence-based guidelines. Nevertheless, pharmacogenetic factors may alter the medication efficacy and worsen the outcome in these patients. Besides, the risk of various cardiovascular events is associated with age and other patients' characteristics, medical history and revascularization 
method [2]. The rate of re-hospitalizations in a 30-day period goes up to $20 \%$ [3,4] in about a quarter due to cardiovascular causes [3]. After 3 months, the rate rises to $9.3 \%$, and up to $20.2 \%$ after a year. Revascularization is needed in approximately 5\% [5]. Known predictors are female sex, CABG surgery or PCI, prior ICD, vascular disease, chronic kidney disease, diabetes mellitus, rheumatic valvular disease, chronic pulmonary disease and anemia [5-7].

Beside patients' characteristics and co-morbidities, primarily decreased, but increased clopidogrel efficacy, as well, may be the reason of poor clinical outcome. Pglycoprotein is a transporter involved in the absorption process of various drugs prescribed in patients with AMI. The presence of polymorphic $\mathrm{T}$ allele of $A B C B 1$ gene may alter their bioavailability, and their pharmacodynamics effects. The absorption of clopidogrel, used in combination with acetylsalicylic acid as dual antiaggregation therapy, is impaired in ABCB1 TT homozygotes, which may account for more than $25 \%$ in Caucasians [8]. Besides, interactions with proton-pump-inhibitors prescribed for gastroprotection, carvedilol (and some other ACE-inhibitors), statins and calcium-channel blockers, via P-glycoprotein inhibition are possible [9]. Other polymorphisms of importance are on the genes encoding cytochrome P450 enzymes, particularly CYP2C19 and CYP2C9. Both of them are involved in the clopidogrel transformation into active metabolite. The induction or inhibition of these enzymes, as well as the other CYP involved in clopidogrel biotransformation, such as CYP3A4, may lay in the basis of significant drug interactions [10].

The aim of this study was to determine the risk factors in patients on clopidogrel anti-platelet therapy after acute myocardial infarction, for cardiovascular mortality, re-hospitalization and admission to emergency care unit.

\section{Subjects and Methods}

The study was approved by Ethics Committee of the University of Niš, Faculty of Medicine. All the subjects were treated in accordance with the Declaration of Helsinki. Before being recruited, each patient gave an informed consent. It was designed as a prospective cohort study.

Patients included in the study were treated at the Clinic of Cardiology, Clinical Center Niš, Serbia. They were recruited upon acute coronary syndrome with/without STelevation diagnosis with biochemical and electrocardiographical confirmation. We followed 175 patients, both with STEMI (75.2\%) and NSTEMI (20.9\%). Half of the patients $(49.7 \%)$ were treated with primary PCI. Thirty-six patients $(20.6 \%)$ were revascularized with fibrinolytics administration, alteplase $(18.9 \%)$ or streptokinase $(1.7 \%)$. Among alteplase patients, $7(4.0 \%)$ underwent rescue PCI. Conventional therapy was applied to the rest $29.7 \%$ patients.
Study group characteristics are shown in Table 1. There were 122 male $(69.7 \%)$ and 53 female $(30.3 \%)$ patients. Their age varied from 30 to 89 years (average $60.80 \pm 11.33$ years)

Table 1 Baseline characteristics of the study patients group

\begin{tabular}{|c|c|}
\hline & mean \pm SD \\
\hline Age (years) & $60.81 \pm 11.29$ \\
\hline Heart rate (1/min.) & $79.60 \pm 19.08$ \\
\hline Systolic blood pressure $(\mathrm{mmHg})$ & $130.92 \pm 26.81$ \\
\hline Diastolic blood pressure $(\mathrm{mmHg})$ & $79.79 \pm 16.02$ \\
\hline Ejection fraction $(\%)$ & $50.77 \pm 11.70$ \\
\hline End-systolic dimension (mm) & $52.33 \pm 6.55$ \\
\hline End-diastolic dimension (mm) & $37.35 \pm$ \\
\hline Right ventricular systolic pressure $(\mathrm{mmHg})$ & $34.82 \pm 11.71$ \\
\hline Left atrial size $(\mathrm{mm})$ & $39.76 \pm$ \\
\hline Body-mass index $\left(\mathrm{kg} / \mathrm{m}^{2}\right)$ & $26.99 \pm$ \\
\hline Cholesterol (mmol/l) & $5.58 \pm$ \\
\hline LDL (mmol/l) & $3.62 \pm$ \\
\hline HDL (mmol/l) & $1.12 \pm$ \\
\hline Triglycerides (mmol/l) & $2.01 \pm$ \\
\hline Hemoglobin (g/l) & $138.91 \pm 19.51$ \\
\hline Hematocrit (1/1) & $0.41 \pm 0.06$ \\
\hline Platelets $\left(10^{9} / 1\right)$ & $253.03 \pm 78.75$ \\
\hline Leukocytes $\left(10^{9} / 1\right)$ & $11.82 \pm 10.91$ \\
\hline Erythrocytes $\left(10^{12} / 1\right)$ & $4.69 \pm$ \\
\hline $\operatorname{AST}(\mathrm{U} / \mathrm{l})$ & $138.52 \pm 170.49$ \\
\hline $\operatorname{ALT}(\mathrm{U} / \mathrm{l})$ & $45.25 \pm 49.47$ \\
\hline LDH (U/l) & $934.33 \pm 769.07$ \\
\hline Glucose $(\mathrm{mmol} / \mathrm{l})$ & $8.28 \pm 4.56$ \\
\hline Creatinine $(\mu \mathrm{mol} / \mathrm{l})$ & $103.41 \pm 44.72$ \\
\hline Creatinine clearance (ml/min.) & $79.28 \pm 25.71$ \\
\hline Urea $(\mathrm{mmol} / \mathrm{l})$ & $6.76 \pm 3.20$ \\
\hline Sodium $(\mathrm{mmol} / \mathrm{l})$ & $136.33 \pm 10.31$ \\
\hline Potassium (mmol/l) & $4.33 \pm 0.48$ \\
\hline $\mathrm{CRP}(\mathrm{mg} / \mathrm{l})$ & $18.28 \pm 32.55$ \\
\hline Troponins (ng/l) & $12.82 \pm 28.47$ \\
\hline Creatine kinase (U/l) & $1052.74 \pm 1403.40$ \\
\hline CKMB (U/l) & $100.86 \pm 126.35$ \\
\hline \multirow[t]{2}{*}{ Fibrinogen $(\mathrm{g} / \mathrm{l})$} & $4.63 \pm$ \\
\hline & $(\%)$ \\
\hline Male & $122(69.7 \%)$ \\
\hline STEMI & $135(77.1 \%)$ \\
\hline Previous AMI & $31(17.7 \%)$ \\
\hline Hypertension & $110(62.9 \%)$ \\
\hline DM & $49(28.0 \%)$ \\
\hline Atrial fibrillation & $16(9.1 \%)$ \\
\hline Smoking & $60(34.3 \%)$ \\
\hline
\end{tabular}

Pharmacological therapy was carried out according to the guidelines. All the patients received antiplatelet and anticoagulant drugs. Antiaggregation therapy was achieved with ASA (98.3\%) and clopidogrel (100.0\%). The therapy of AMI consisted of ACE inhibitors (68.4\%), beta-blockers $(75.4 \%)$, diuretics $(20.6 \%)$, spironolactone $(17.7 \%)$, calcium channel blocker $(11.4 \%)$, amiodarone $(10.3 \%)$, digoxin $(6.3 \%)$, long-lasting vasodilators $(24.6 \%)$ and trimetazidine (10.3\%), as well. Besides, they were given lipid-lowering statins $(94.3 \%)$, pantoprazole for gastroprotection (90.3\%) and anxiolytics (33.7\%). 
Table 2 Primers used for SNPs detection

\begin{tabular}{ll}
\hline ABCB1 C3435T & C (5'-GGTGTCACAGGAAGAGATC-3') \\
& T (5'-CAGCCGGGTATAGTCACAGGAAGATATT-3') \\
& Reverse (5'-GGCCAGAGAGGCTGCCACAT-3') \\
\hline CYP2C19*2 & Forward (5'-AATTACAACCAGAGCTTGGC-3') \\
& Reverse (5'-TATCACTTTCCATAAAAGCAAG-3') \\
\hline CYP2C19*17 & Forward (5'-GCCCTTAGCACCAAATTCTC-3') \\
& Reverse (5'-ATTTAACCCCCTAAAAAAACACG-3') \\
\hline CYP2C9*2 & Forward (5'-GTATTTTGGCCTGAAACCCATA-3') \\
& Reverse (5'-GGCCTTGGTTTTCTCAACTC-3') \\
\hline
\end{tabular}

Thirty-one patients (17.7\%) had previous AMI (reinfarction patients were excluded from the study). Among co-morbidities, $110(62.9 \%)$ had HTA diagnosed for $11.29 \pm 8.61$ years, while $49(28.0 \%)$ suffered from diabetes mellitus type 2 for approximately $8.64 \pm 7.83$ years, and 16 patients $(9.1 \%)$ had atrial fibrillation. Anamnestic data showed that one third of the patients $(34.3 \%)$ were current smokers (former smokers were considered non-smokers).

Accrual time was 1 year, while the follow-up time was 6 months. During that period patients were monitored for reporting to the emergency unit, re-hospitalizations and mortality. Non-related non-cardiovascular events were not included into analysis.

During the accrual and follow-up period, all the patients were genotyped for ABCB1 C34335T (rs1045642), CYP2C19*2 (rs4244285) and *17 (rs12248560), as well as CYP2C9*2 (rs1799853). From each collected whole blood sample, we have isolated genomic DNA manually. Using the PCR-RFLP (polymerase chain reaction-restriction fragment length polymorphism) method and specific primers (Table 2), before-mentioned small nuclear polymorphisms (SNPs) were detected.

Statistical Package for Social Sciences (SPSS 16.0; Chicago, Ill., USA) was used for statistical data analysis. Baseline characteristics are presented as frequencies or means with SDs. Quantitative variables were compared between groups using Student's t-test, while for qualitative variables Fisher's exact test was performed. A $p$ value $<0.05$ was considered to be a measure of statistical significance. Using Cox-regression, hazard ratios and $95 \%$ CIs were calculated, and therefore, potentiated the comparison of outcome occurrence between groups and the effect of each predictor.

\section{Results}

During the accrual and follow-up period, 8 patients $(4.6 \%)$ died. In 6 cases it was the direct consequence of an acute myocardial infarction. The other two deaths both had cardiovascular cause: infective myocarditis and lower extremity thrombosis. They occurred between 7 and 297 days after the recruitment. Re-hospitalization was needed in 27 patients $(15.4 \%)$. Most of them were re-hospitalized only once during the follow-up period, while the maximum number of re-hospitalizations was 7 in one case. Nine patients $(33.3 \%)$ were re-hospitalized with the diagnosis of re-infarction. In one of the cases the re-infarction was caused by stent thrombosis. The symptoms of angina pectoris, stable $(22.2 \%)$ or unstable $(11.1 \%)$, were the reason for re-admission reported as well. Thirty-two patients $(18.3 \%)$ were admitted to emergency care unit due to cardiovascular causes, up to 15 times during the follow-up.

ABCB1 C3435T genotyping was $100.0 \%$ successful, while in 51 patients $(29.1 \%)$ we could not determine CYP2C19 and CYP2C9 polymorphism. The observed genotype frequencies did not deviate significantly from those expected at Hardy-Weinberg equilibrium (Table 3).

Table 3 ABCB1 C3435T, CYP2C19 and CYP2C9 genotype frequencies

\begin{tabular}{lcrc}
\hline Gene & Genotype & N (f) & $\chi^{2}(\mathrm{p})$ \\
\hline ABCB1 C3435T & CC & $41(23.4 \%)$ & \\
& CT & $81(46.3 \%)$ & $0.658(0.720)$ \\
& TT & $53(30.3 \%)$ & \\
\hline CYP2C19 & PM & $5(4.0 \%)$ & \\
& IM & $33(26.6 \%)$ & $4.649(0.460)$ \\
& EM & $46(37.1 \%)$ & \\
& URM & $40(32.3 \%)$ & \\
\hline CYP2C9 & CC & $115(79.3 \%)$ & \\
& CT & $28(19.3 \%)$ & $4.634(0.099)$ \\
& TT & $2(1.4 \%)$ & \\
\hline
\end{tabular}

Table 4 Cardiovascular outcomes in relation to genotype

\begin{tabular}{lccc}
\hline & $\begin{array}{c}\text { Emergency care unit } \\
\text { admission (HR (CI 95\%), p) }\end{array}$ & $\begin{array}{c}\text { Re-hospitalization } \\
(\text { HR (CI 95\%), p) }\end{array}$ & $\begin{array}{c}\text { Cardiovascular death } \\
(\text { HR (CI 95\%), p) }\end{array}$ \\
\hline ABCB1 genotype (CC-CT-TT) & $1.2(0.7-1.9), 0.526$ & $1.4(0.9-2.5), 0.170$ & $0.5(0.2-1.4), 0.221$ \\
ABCB1 TT genotype & $0.9(0.4-2.0), 0.866$ & $1.3(0.6-2.8), 0.556$ & $0.3(0.0-2.7), 0.298$ \\
ABCB1 any T allele & $1.8(0.7-4.8), 0.216$ & $2.7(0.8-9.1), 0.102$ & $0.5(0.1-2.1), 0.348$ \\
CYP2C19 phenotype (SM-IM-EM-URM) & $0.8(0.5-1.2), 0.245$ & $0.9(0.5-1.4), 0.528$ & $0.8(0.4-2.0), 0.694$ \\
CYP2C19 any *2 allele & $1.5(0.7-3.3), 0.309$ & $1.4(0.6-3.4), 0.442$ & $1.8(0.4-7.9), 0.460$ \\
CYP2C19 any *17 allele & $0.8(0.4-1.8), 0.612$ & $1.0(0.4-2.5), 0.885$ & $0.5(0.1-2.7) .0 .448$ \\
CYP2C9 any *2 allele & $0.4(0.1-1.3), 0.128$ & $0.7(0.2-2.1), 0.553$ & $0.6(0.1-5.4), 0.686$ \\
\hline
\end{tabular}


As genetic predictors, we have analyzed the presence of various genotypes and phenotypes of ABCB1, CYP2C19 and CYP2C9 genes. For each of the three outcomes monitored, none of the predictors were shown to be statistically significant (Table 4).

We have tested the patients' characteristics, co-morbidities and social habits such as smoking as risk predictors of cardiovascular outcomes (Table 5-7). Even though univariate Cox-regression analysis have identified a number of statistically significant predictors of need for re-hospitalization (Table 5), after their inclusion into a multivariate model $\left(\chi^{2}=18.522, \mathrm{p}<0.001\right)$, the only predictors that remained independently significant were the type of AMI, with or without ST-segment elevation, and clopidogrel dosing regimen. Patients after NSTEMI had 2.8 higher risk $(\mathrm{p}<0.05)$ of re-hospitalization due to cardiovascular indications. Patients with lower dose clopidogrel dosing regimens (lower or no loading dose) had 2.3 times higher risk of re-hospitalization $(\mathrm{p}<0.05)$.
Considering emergency care unit admission, due to cardiovascular symptoms and signs (Table 6), the majority of predictors identified by univariate Cox-regression modeling, remained independently significant in the multivariate model $\left(\chi^{2}=35.662, \mathrm{p}<0.001\right)$. In comparison to STEMI, NSTEMI is associated with 2.4 times higher risk $(\mathrm{p}<0.05)$. High LDL (above $3 \mathrm{mmol} / \mathrm{l}$ ) leads to 2.5 times lower risk $(\mathrm{p}<0.05)$. Patients with decreased LVEF after AMI, below 45\%, had 3 times $(\mathrm{p}<0.05)$ higher risk of need for emergence care. Increased creatinine concentration, for each $10 \mu \mathrm{mol} / \mathrm{l}$, increases the risk 1.1 times $(\mathrm{p}<0.001)$. Patients with HTA are at 3 times higher risk $(p<0.05)$ of emergency care need. Among the drugs prescribed, therapy with calcium channel blockers increased the risk by 2.8 times $(\mathrm{p}<0.05)$.

Despite low mortality, we have identified (Table 7) two significant predictors in a multivariate Coxregression model $\left(\chi^{2}=15.137, \mathrm{p}<0.01\right)$. Acute myocardial infarction without ST-segment elevation was associated with 7.4 higher risk of cardiovascular mortality $(\mathrm{p}<0.05)$. The increase in urea concentration for each unit augments the risk 1.1 times $(\mathrm{p}<0.05)$.

Table 5 Predictors of re-hospitalization due to cardiovascular causes

\begin{tabular}{|c|c|c|}
\hline $\begin{array}{l}\text { Re-hospitalization } \\
\text { (HR (CI 95\%), p) }\end{array}$ & Univariate Cox-regression & Multivariate Cox-regression \\
\hline Age (years) & $1.041(1.005-1.078), 0.024$ & \\
\hline NSTEMI vs. STEMI & $4.148(1.948-8.829), 0.000$ & 2.785 (1.102-7.038), 0.030 \\
\hline High LDL $>3 \mathrm{mmol} / \mathrm{l}$ & $0.407(0.176-0.942), 0.036$ & \\
\hline Hemoglobin $(\mathrm{g} / \mathrm{l})$ & $0.982(0.965-1.000), 0.047$ & \\
\hline Leukocytes $\left(10^{9} / 1\right)$ & $0.817(0.679-0.983), 0.032$ & \\
\hline AST (U/L) & $0.994(0.988-0.999), 0.032$ & \\
\hline Creatinine $(\mu \mathrm{mol} / \mathrm{l})$ & $1.006(1.000-1.011), 0.035$ & \\
\hline Urea $(\mathrm{mmol} / \mathrm{l})$ & $1.095(1.019-1.178), 0.014$ & \\
\hline $\mathrm{CK}(\mathrm{U} / \mathrm{L})$ & $0.999(0.999-1.000), 0.049$ & \\
\hline Previous AMI & $4.102(1.919-8.771), 0.000$ & \\
\hline HTA & $5.069(1.526-16.835), 0.008$ & \\
\hline DM type 2 & $2.214(1.036-4.732), 0.040$ & \\
\hline Clopidogrel loading dose (mg) & $0.996(0.994-0.998), 0.000$ & \\
\hline Clopidogrel loading dose $/ \mathrm{BMI}\left(\mathrm{mg} \cdot \mathrm{m}^{2} / \mathrm{kg}\right)$ & $0.905(0.838-0.977), 0.011$ & \\
\hline Clopidogrel dosing regimen $(\mathrm{mg})$ & $2.356(1.227-4.522), 0.010$ & $2.284(1.136-4.593), 0.020$ \\
\hline Carvedilol vs. Bisoprolol & $3.060(1.099-8.518), 0.032$ & \\
\hline Diuretic & $2.927(1.358-6.308), 0.006$ & \\
\hline Spironolactone & 2.835 (1.298-6.192), 0.009 & \\
\hline Long lasting nitrates & $2.557(1.196-5.463), 0.015$ & \\
\hline
\end{tabular}

Table 6 Predictors of emergency care due to cardiovascular causes

\begin{tabular}{lcc}
\hline $\begin{array}{l}\text { Emergency care unit admission } \\
(\mathrm{HR}(\mathrm{CI} 95 \%), \mathrm{p})\end{array}$ & Univariate Cox-regression & Multivariate Cox-regression \\
\hline NSTEMI & $3.071(1.512-6.240), 0.007$ & $2.379(1.080-5.243), 0.031$ \\
High LDL $>3 \mathrm{mmol} / \mathrm{l}$ & $0.431(0.205-0.907) 0.027$ & $0.399(0.181-0.881), 0.023$ \\
EF $<45 \%$ & $2.395(1.191-4.817), 0.014$ & $3.044(1.398-6.629), 0.005$ \\
Creatinine $(\mu \mathrm{mol} / \mathrm{l})$ & $1.009(1.004-1.014), 0.001$ & $1.011(1.004-1.017), 0.001$ \\
Urea $(\mathrm{mmol} / \mathrm{l})$ & $1.152(1.067-1.243), 0.000$ & \\
HTA & $2.867(1.179-6.969), 0.024$ & $3.133(1.200-8.180), 0.020$ \\
Diuretic & $2.479(1.212-5.072), 0.013$ & \\
Calcium channel blocker & $2.664(1.151-6.168), 0.022$ & $2.782(1.000-7.738), 0.050$ \\
\hline
\end{tabular}


Table 7 Predictors of cardiovascular mortality

\begin{tabular}{lrc}
\hline $\begin{array}{l}\text { Cardiovascular mortality } \\
(\mathrm{HR}(\mathrm{CI} 95 \%), \mathrm{p})\end{array}$ & Univariate Cox-regression & Multivariate Cox-regression \\
\hline NSTEMI & $11.019(2.223-54.615), 0.003$ & $7.431(1.371-40.267), 0.020$ \\
LDL $(\mathrm{mmol} / \mathrm{l})$ & $0.514(0.281-0.940), 0.031$ & \\
High LDL $3 \mathrm{mmol} / \mathrm{l}$ & $0.217(0.049-0.970), 0.046$ & \\
Hemoglobin $(\mathrm{g} / \mathrm{l})$ & $0.966(0.938-0.995), 0.021$ & \\
Creatinine $(\mu \mathrm{mol} / \mathrm{l})$ & $1.009(1.003-1.015), 0.004$ & \\
Creatinine clearance $(\mathrm{ml} / \mathrm{min})$. & $0.933(0.886-0.983), 0.009$ & \\
Urea $(\mathrm{mmol} / \mathrm{l})$ & $1.162(1.073-1.257), 0.000$ & $1.094(1.001-1.195), 0.046$ \\
Previous AMI & $4.820(1.205-19.277), 0.026$ & \\
Clopidogrel loading dose $(\mathrm{mg})$ & $0.994(0.990-0.999), 0.016$ & \\
Clopidogrel dosing regimen $(\mathrm{mg})$ & $5.190(1.166-23.107), 0.031$ & \\
Acetylsalicylic acid loading dose $(\mathrm{mg})$ & $0.993(0.986-0.999), 0.034$ & \\
Calcium channel blocker & $5.004(1.195-20.946), 0.027$ & \\
\hline
\end{tabular}

\section{Discussion}

After a 1-year follow-up of patients after AMI, 4.6\% died, $15.4 \%$ were re-hospitalized and $33.3 \%$ visited emergency unit, all associated with cardiovascular events. These rates are slightly lower than those reported in previous studies $(1,3-5)$. One of the risk factors for poor clinical outcome, regarding all three events registered is NSTEMI. Compared to STEMI patients, NSTEMI patients are associated with 2.4 times higher risk of emergency care needed, 2.8 times higher risk of re-hospitalization, and even 7.4 times higher risk of cardiovascular death. It is suggested that STEMI patients are favored by rapid revascularization and more aggressive pharmacotherapy, resulting in lower rate of mortality and re-hospitalizations in 1-year period after AMI [11].

Elevated creatinine concentration was found to be and independent predictor of re-hospitalizations, while elevated urea concentration was associated with increased risk of cardiovascular mortality. Patients with chronic kidney disease, especially those with more severe stages, are less likely to be revascularized and prescribed evidence-based therapy. On the other hand, they presented more often with bleeding complications. When summed up, this results in higher mortality rate, particularly in STEMI patients [12].

Higher clopidogrel dosing regimen was found to be associated with lower risk of re-hospitalizations. When higher clopidogrel doses are administered, the production of clopidogrel active metabolite is multiplied, despite some saturation of the pharmacokinetic processes involved [13]. In the elderly, no loading dose is recommended, while lower loading dose is prescribed in patients administered fibrinolytics [14]. High loading dose gives the greatest benefit in the first days after AMI, but increased maintenance dose, recommended in the first week, significantly decreases the risk of major adverse cardiovascular events [15].
Hyperlipidemia is a known risk factor for ACS and for the worse prognosis after AMI [16]. Our results have shown that high LDL favored good prognosis, as found in similar studies [17]. This may be due to the therapy with statins. Beside lowering LDL, these drugs have a number of pleiotropic effects in atherosclerotic diseases. Statins may have antithrombotic effect, directly diminishing the possibility of various cardiovascular events, due to inhibited platelet and activation and procoagulant protein tissue factor expression [18]. Besides, there are significant changes in atherosclerotic plaque characteristics in patients receiving statin therapy, concerning calcium and fibrous deposition, as well as its elastic membrane, thus stabilizing the plaque [19].

After suffering AMI, in a large number of patients there is a decrease in left ventricular EF. This worsening of the cardiac contractile function is one of the prognostic factors for bad prognosis. The risk increases at least 3 times $[17,20]$, as found in our results. Mild and severe left ventricular dysfunctions are associated with higher risk in patients with AMI, especially in combination with co-morbidities [21].

We have found patients with HTA to be at more than 3 times higher risk of suffering from cardiovascular symptoms during the follow-up period after AMI. In the previous studies, somewhat lower hazard risk ratio was found for these patients to experience major adverse cardiovascular events [22,23], but it may rise to 5 times higher risk in patients with unspecified chest pain [24]. Therefore, patients on antihypertensive drugs, such as calcium channel blockers, were associated with worse prognosis, as well.

Although there are numerous studies suggesting the association between genetic profile, including cytochrome P450 enzymes and P-glycoprotein, and outcome in patients after AMI [25-27], we have not obtained statistically significant results. This may be explained by insufficient number of events for such genetic analysis. Except for $\mathrm{ABCB} 1$ polymorphisms for P-glycoproteins, low-function genotypes are rare in the Caucasian population. 


\section{Conclusion}

As a conclusion, we may imply that one of the most significant predictor of cardiovascular events (mortality, re-hospitalization and emergency care visits) is NSTEMI. Besides, clopidogrel administration according to up-to-date guidelines, with high loading doses and initial doubled maintenance doses, improves 1-year prognosis in patients with AMI.

\section{References}

1. Ilic D, Miljus D, Mickovski Katalina N, Plavsic S, Bozic Z. Incidence and mortality of acute coronary syndromes in Serbia. Serbian Acute Coronary Syndrome Registry Report No. 9. Miljus D, Mickovski Katalina N, Plavsic S, Bozic Z, editors. Beograd: Institute of Public Health of Serbia "Dr Milan Jovanovic Batut"; 2015.

2. Jernberg T, Hasvold P, Henriksson M, Hjelm H, Thuresson M, Janzon M. Cardiovascular risk in post-myocardial infarction patients: nationwide real world data demonstrate the importance of a long-term perspective. Eur Heart J 2015; 36(19):1163-1170.

3. Krumholz HM, Lin Z, Drye EE, et al. An Administrative Claims Measure Suitable for Profiling Hospital Performance Based on 30Day All-Cause Readmission Rates Among Patients With Acute Myocardial Infarction. Circ Cardiovasc Qual Outcomes 2011; 4:243-252.

4. Brown JR, Chang C-H, Zhou W, MacKenzie TA, Malenka DJ, Goodman DC. Health System Characteristics and Rates of Readmission After Acute Myocardial Infarction in the United States. J Am Heart Assoc 2014; 3:e000714.

5. Arnold S V., Smolderen KG, Kennedy KF, et al. Risk Factors for Rehospitalization for Acute Coronary Syndromes and Unplanned Revascularization Following Acute Myocardial Infarction. J Am Heart Assoc 2015; 4:e001352

6. Rodriguez-Padial L, Elola FJ, Fernández-Pérez C, et al. Patterns of inpatient care for acute myocardial infarction and 30-day, 3-month and 1-year cardiac diseases readmission rates in Spain. Int $\mathbf{J}$ Cardiol 2017; 230:14-20.

7. Rana S, Tran T, Luo W, Phung D, Kennedy RL, Venkatesh S. Predicting unplanned readmission after myocardial infarction from routinely collected administrative hospital data. Aust Heal Rev 2014; 38(4):377.

8. Stokanovic D, Nikolic VN, Konstantinovic SS, et al. PGlycoprotein Polymorphism C3435T Is Associated with DoseAdjusted Clopidogrel and 2-Oxo-Clopidogrel Concentration. Pharmacology 2016; 97(3-4):101-106

9. Wessler JD, Grip LT, Mendell J, Giugliano RP. The P-glycoprotein transport system and cardiovascular drugs. J Am Coll Cardiol 2013; 61(25):2495-2502

10. Wang L, McLeod HL, Weinshilboum RM. Genomics and drug response. N Engl J Med 2011 Mar 24;364(12):1144-1153.

11. Montalescot G, Dallongeville J, Van Belle E, et al. STEMI and NSTEMI: are they so different? 1 year outcomes in acute myocardial infarction as defined by the ESC/ACC definition (the OPERA registry). Eur Heart J 2006; 28(12):1409-1417.

12. Fox CS, Muntner P, Chen AY, et al. Use of Evidence-Based Therapies in Short-Term Outcomes of ST-Segment Elevation Myocardial Infarction and Non-ST-Segment Elevation Myocardial Infarction in Patients With Chronic Kidney Disease. Circulation 2010; 121(3):357-365.

13. Jiang X-L, Samant S, Lewis JP, et al. Development of a physiology-directed population pharmacokinetic and pharmacodynamic model for characterizing the impact of genetic and demographic factors on clopidogrel response in healthy adults. Eur J Pharm Sci 2016;82:64-78.

14. Steg PG, James SK, Atar D, et al. ESC Guidelines for the management of acute myocardial infarction in patients presenting with ST-segment elevation. Eur Heart J 2012; 33(20):2569-2619.
Acknowledgements: This study was funded by the grant No. III41018 from the Serbian Ministry of Education, Science and Technological Development.

15. Ma W, Liang Y, Zhu J, Wang Y, Wang X. Meta-Analysis Appraising High Maintenance Dose Clopidogrel in Patients Who Underwent Percutaneous Coronary Intervention With and Without High On-Clopidogrel Platelet Reactivity. Am J Cardiol 2015; 115(5):592-601.

16. Karjalainen PP, Nammas W, Ylitalo A, et al. Long-term clinical outcome of titanium-nitride-oxide-coated stents versus everolimuseluting stents in acute coronary syndrome: Final report of the BASE ACS trial. Int J Cardiol 2016; 222:275-280.

17. Sigurjonsdottir R, Barywani S, Albertsson P, Fu M. Long-term major adverse cardiovascular events and quality of life after coronary angiography in elderly patients with acute coronary syndrome. Int J Cardiol 2016; 222:481-485.

18. Phillip Owens A, Mackman N. The Antithrombotic Effects of Statins. Annu Rev Med 2014; 65(1):433-445.

19. Pundziute G, Schuijf JD, Jukema JW, Decramer I, Sarno G, Vanhoenacker PK, et al. Evaluation of plaque characteristics in acute coronary syndromes: non-invasive assessment with multislice computed tomography and invasive evaluation with intravascular ultrasound radiofrequency data analysis. Eur Heart J 2008; 29(19):2373-2381.

20. Yuan M-J, Pan Y-S, Hu W-G, et al. A pilot study of prognostic value of non-invasive cardiac parameters for major adverse cardiac events in patients with acute coronary syndrome treated with percutaneous coronary intervention. Int J Clin Exp Med 2015; 8(12):22440-22449.

21. Perelshtein Brezinov O, Klempfner R, Zekry S Ben, Goldenberg I, Kuperstein R. Prognostic value of ejection fraction in patients admitted with acute coronary syndrome: A real world study. Medicine 2017; 96(9):e6226.

22. Zhou D, Wan Z, Fan Y, Zhou J, Yuan Z. A combination of the neutrophil-to-lymphocyte ratio and the GRACE risk score better predicts PCI outcomes in Chinese Han patients with acute coronary syndrome. Anatol J Cardiol 2015; 15(12):995-1001.

23. Hyun DY, Jeong MH, Sim DS, Jeong YA, Cho KH, Kim MC, et al. Two-year clinical outcomes in stable angina and acute coronary syndrome after percutaneous coronary intervention of left main coronary artery disease. Korean J Intern Med 2016; 31(6):1084-1092.

24. Omstedt ̊, Höijer J, Djärv T, Svensson P. Hypertension predicts major adverse cardiac events after discharge from the emergency department with unspecified chest pain. Eur Hear J Acute Cardiovasc Care 2016; 5(5):441-448.

25. Su J, Xu J, Li X, et al. ABCB1 C3435T polymorphism and response to clopidogrel treatment in coronary artery disease (CAD) patients: a meta-analysis. PLoS One 2012; 7(10):e46366.

26. Simon T, Verstuyft C, Mary-Krause M, et al. Genetic determinants of response to clopidogrel and cardiovascular events. N Engl J Med 2009; 360(4):363-375.

27. Wallentin L, James S, Storey RF, et al. Effect of CYP2C19 and $\mathrm{ABCB} 1$ single nucleotide polymorphisms on outcomes of treatment with ticagrelor versus clopidogrel for acute coronary syndromes: a genetic substudy of the PLATO trial. Lancet 2010; 376(9749):1320-1328. 